Immunodeficiencies

\title{
Injecting some safety into SCID gene therapy?
}

F Candotti, C Roifman and JM Puck

Gene Therapy (2006) 13, 741-743. doi:10.1038/sj.gt.3302663;

published online 20 October 2005

A new study in a mouse model shows that in situ corrective gene transfer can restore T-cell development in a form of severe combined immunodeficiency (SCID) but will this approach translate into safer gene therapy for human T-cell deficiencies?

Gene transfer ex vivo into hematopoietic progenitor cells using vectors based on gamma-retroviruses has been shown to be a successful therapeutic option for SCID. ${ }^{1-4}$ The occurrence of insertional oncogenesis events in one trial, ${ }^{5,6}$ however, has indicated the need to explore other gene transfer vectors and approaches.

Lentiviral vectors have been proposed as a safer alternative for a number of reasons including their reduced tendency to target gene transcriptional start sites, 7,8 and their amenability to being produced in 'self-inactivating' configurations. ${ }^{9,10}$ Current gene therapy approaches for SCID involve in vitro culture and transduction of hematopoietic progenitors. Although this practice has resulted in long-term (6+ years) engraftment of multilineage progenitors, ${ }^{1-4}$ ex vivo manipulation can be expected to cause some loss of the critical cells with pluripotent hematopoietic stem cell characteristics. ${ }^{11,12}$

In the August issue of The Journal of Clinical Investigation, Adjali et al. ${ }^{13}$ reported results relevant to both the above issues. These investigators used direct intrathymic injection of a lentiviral vector to correct a mouse model of the form of SCID due to deficiency of ZAP-70, the T-cell receptor $\zeta$-chain-associated signaling kinase specific to $\mathrm{T}$ and NK cells (reviewed in Roifman, ${ }^{14}$ ). Following intrathymic injection, functional $\mathrm{T}$ cells appeared in about a quarter of the treated mice, indicating reversal of the thymocyte differentiation block characteristic of ZAP-70 deficiency as well as a selective advantage for corrected T-lineage cells. ${ }^{13}$

ZAP-70 deficiency is an exceedingly rare form of SCID in humans and is unique, in that nonfunctional CD4+ $\mathrm{T}$ cells are found in the circulation, although CD8 $+\mathrm{T}$ cells are absent. ${ }^{14}$ An obvious question that arises is whether direct intrathymic injection of a corrective vector could be exploited for the more common gene defects causing SCID, such as X-linked SCID (X-SCID) and deficiencies of JAK3 kinase, adenosine deaminase (ADA), recombinase activating genes (RAG1, RAG2), or Artemis.

The histology of the thymus differs markedly in ZAP-70 deficiency, in which there is a relatively late blockage of T-cell receptor signaling, compared to these more typical forms of SCID, in which thymi have developmental arrest at the prethymic or early preproliferative thymic stages. ${ }^{14}$ In both murine and human ZAP-70 deficiency, the thymus is of normal size and contains a full complement of cortical thymocytes as well as abundant medullary thymocytes of the CD4 lineage. More typical human SCIDs, such as the $\gamma_{c}$ deficient X-SCID case illustrated in Figure 1, have extremely small thymi, generally $<1 \mathrm{~g}$, which are made up of vestigial, empty stromal tissue virtually devoid of thymocytes. Thus, even if the thymic stromal remnant could be localized and injected, very few to no T-lineage cells would be available for gene correction of X-SCID or other typical SCIDs. Indeed, transduction of thymic stromal cells would be the expected outcome of vector injection into the thymi of such patients, a phenomenon noted in the experiments of Adjali et al. ${ }^{13}$ The potential consequences of insertion into stromal cell genomes of vectors contain- ing the CD4 enhancer used by Adjali et al. are unknown.

As pointed out by these authors, the clinical improvement of an X-SCID patient with spontaneous in vivo reversion of his mutation indicated that correction of perhaps even a single $\mathrm{T}$-cell precursor can result in amelioration of the clinical phenotype due to the strong selective advantage of cells with intact $\gamma \mathrm{c} .{ }^{15}$ So it might be possible that gene transfer into even a scarcely populated thymus could afford some prospect of meaningful T-cell production. Eventually, however, the revertant $\mathrm{T}$-cell population that had emerged in the cited X-SCID patient exhausted itself, necessitating bone marrow transplantation treatment. So the logical next question is: what could be the expected longevity of thymic T-cell precursors after in situ gene correction?

Mice that the authors treated retained gene corrected thymocytes as long as 52 weeks after gene transfer, ${ }^{13}$ approximately half the life expectancy of the average laboratory mouse. However, converting mouse years into human years remains a questionable proposition; the intrathymic procedure might have to be undertaken repeatedly in humans. Moreover, achieving a fully diverse repertoire of corrected $\mathrm{T}$ cells could require multiple gene injections, since this did not happen after the single intrathymic injection given to the ZAP-70 knockout mice. ${ }^{13}$

The results by Adjali et al. ${ }^{13}$ offer a potential new strategy for gene therapy of ZAP-70 deficiency and perhaps other selected T-cell immunodeficiencies with conserved thymic structure and cellularity, such as deficiencies of the $\delta$ and $\varepsilon$ components of the CD3 receptor complex. However, as the authors point out, to achieve reliable, full correction of treated animals and reconstitution of responses to pathogens, the efficacy of intrathymic gene transfer will need to be improved. Moreover, to validate the postulated safety features of T-cell-specific lentiviral gene therapy the field needs to assess the genomic distribution of vector insertions in transduced $\mathrm{T}$ lymphocytes, the potential for the vector's CD4 enhancer to cis-activate neighboring genes, and any cooperativity between the ZAP-70 kinase and endogenous gene products that 

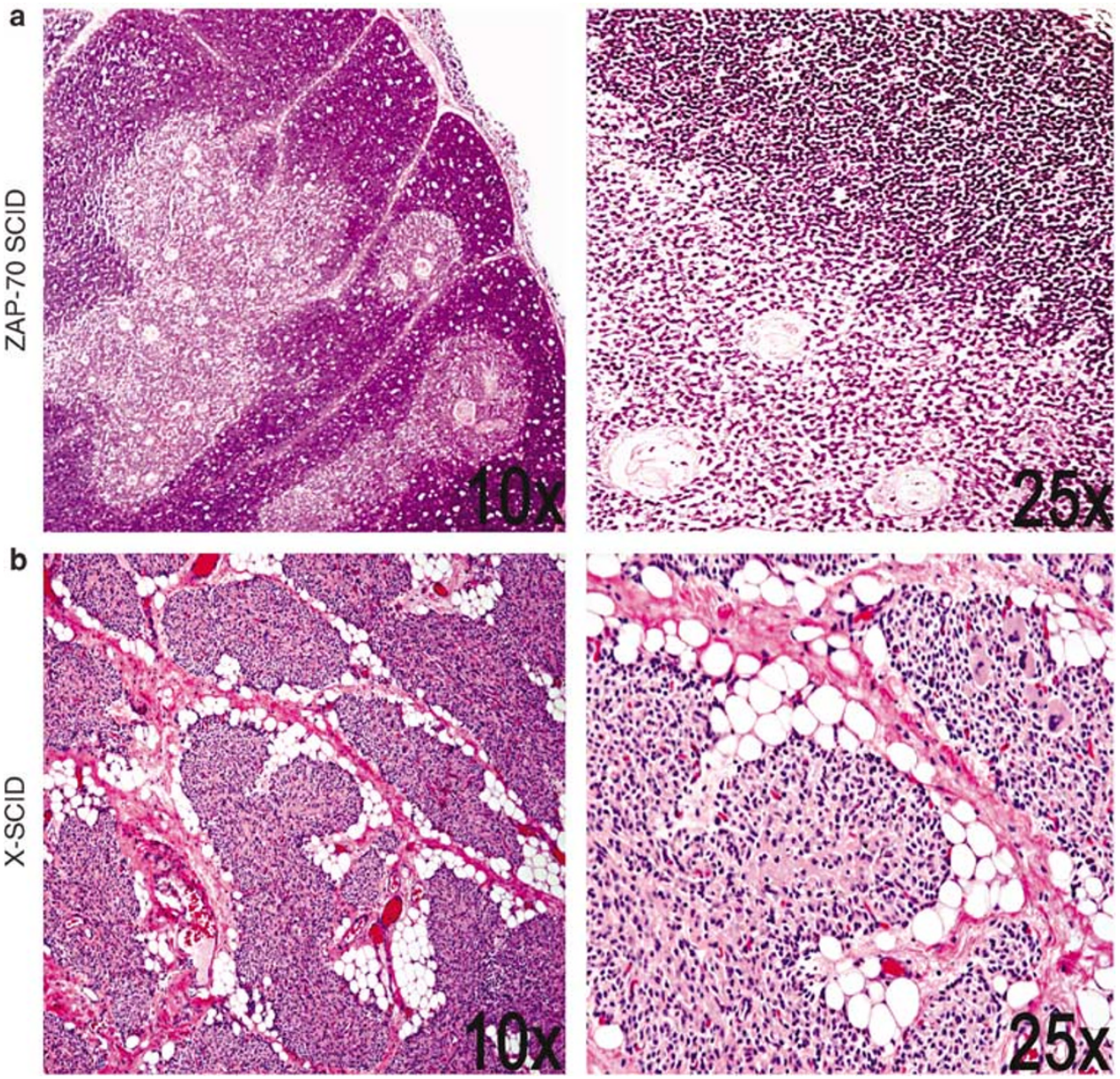

Figure 1 Comparative thymus histology showing hematoxlin and eosin staining at lower (left panels) and higher (right panels) magnification. (a) ZAP-70 deficiency, showing clearly distinct cortical and medullary regions at low magnification, and fully formed Hassall's corpuscles and normal lymphocyte cellularity at high magnification. (b) X-SCID, showing dysplastic gland with architecture barely recognizable due to complete depletion of thymocytes, fibrosis, and the lack of Hassall's Corpuscles. Most cells observed are large epitheloid cells.

could confer a risk of malignant transformation.

Gene therapy for forms of SCID that affect development and/or function of $\mathrm{B}$ and/or NK cells in addition to $\mathrm{T}$ cells will still need to target pluripotent hematopoietic progenitors resident in the bone marrow, rather than limiting the transduction to $\mathrm{T}$ cell progenitors in the thymus. While current clinical protocols have been based on ex-vivo manipulation of such cells, it is foreseeable that intraosseous administration of viral vectors could produce in situ correction in future, as has already been proven successful in several animal models, including Jak3-deficient SCID mice. ${ }^{16-19}$

An ultimate goal of gene therapy is the development of safe gene vectors that can be administered simply as drugs. The work by Adjali et al..$^{13}$ represents an early, but interesting step toward this goal, a step that could have important implications for the future treatment options of ZAP-70 deficiency. Whether this approach can be beneficial for the majority of SCIDs with few to no T-cell targets for correction in the thymus remains to be evaluated.

JM Puck and F Candotti are at the Genetics and Molecular Biology Branch, National Human Genome Research Institute, NIH Bldg $49 \mathrm{Rm}$ 4A414, 49 Convent Drive, Bethesda, MD, 20892, USA

E-mail: jpuck@mail.nih.gov

C Roifman is at the Division of Immunology and Allergy, and Program of Infection, Immunity, Injury and Repair, The Hospital for Sick Children, University of Toronto, Toronto, Ontario, Canada

1 Cavazzana-Calvo M, Hacein-Bey S, de Saint Basile G, Gross F, Yvon E, Nusbaum $P$ et al. Gene therapy of human severe combined immunodeficiency (SCID)-X1 disease. Science 2000; 288: 669-672.
2 Aiuti A, Slavin S, Aker M, Ficara F, Deola S, Mortellaro A et al. Correction of ADA-SCID by stem cell gene therapy combined with nonmyeloablative conditioning. Science 2002; 296: 2410-2413.

3 Hacein-Bey-Abina S, Le Deist F, Carlier F, Bouneaud C, Hue C, De Villartay JP et al. Sustained correction of X-linked severe combined immunodeficiency by ex vivo gene therapy. N Engl J Med 2002; 346: 1185-1193.

4 Gaspar HB, Parsley KL, Howe S, King D, Gilmour KC, Sinclair J et al. Gene therapy of $\mathrm{X}$-linked severe combined immunodeficiency by use of a pseudotyped gammaretroviral vector. Lancet 2004; 364: 2181-2187.

5 Hacein-Bey-Abina S, von Kalle C, Schmidt M, Le Deist F, Wulffraat N, McIntyre $\mathrm{E}$ et al. A serious adverse event after successful gene therapy for $\mathrm{X}$ linked severe combined immunodeficiency. N Engl J Med 2003; 348: 255-256.

6 Hacein-Bey-Abina S, Von Kalle C, Schmidt M, McCormack MP, Wulffraat $\mathrm{N}$, Leboulch $\mathrm{P}$ et al. LMO2-associated 
clonal T cell proliferation in two patients after gene therapy for SCID-X1. Science 2003; 302: 415-419.

$7 \mathrm{Wu} \mathrm{X,} \mathrm{Li} \mathrm{Y,} \mathrm{Crise} \mathrm{B,} \mathrm{Burgess} \mathrm{SM.}$ Transcription start regions in the human genome are favored targets for MLV integration. Science 2003; 300: 1749-1751.

8 Mitchell RS, Beitzel BF, Schroder AR, Shinn P, Chen H, Berry CC et al. Retroviral DNA integration: ASLV, HIV, and MLV show distinct target site preferences. PLoS Biol 2004; 2: E234.

9 Dull T, Zufferey R, Kelly M, Mandel RJ, Nguyen M, Trono D et al. A thirdgeneration lentivirus vector with a conditional packaging system. J Virol 1998; 72: 8463-8471.

10 Miyoshi H, Blomer U, Takahashi M, Gage FH, Verma IM. Development of a self-inactivating lentivirus vector. J Virol 1998; 72: 8150-8157.

11 Rebel VI, Tanaka M, Lee JS, Hartnett S, Pulsipher M, Nathan DG et al. One-day ex vivo culture allows effective gene transfer into human nonobese diabetic/ severe combined immune-deficient repopulating cells using high-titer vesicular stomatitis virus $G$ protein pseudotyped retrovirus. Blood 1999; 93: 2217-2224.

12 Dorrell C, Gan OI, Pereira DS, Hawley RG, Dick JE. Expansion of human cord blood CD34(+)CD38(-) cells in ex vivo culture during retroviral transduction without a corresponding increase in SCID repopulating cell (SRC) frequency: dissociation of SRC phenotype and function. Blood 2000; 95: 102-110.

13 Adjali O, Vicente RR, Ferrand C, Jacquet $\mathrm{C}$, Mongellaz $\mathrm{C}$, Tiberghien $\mathrm{P}$ et al. In vivo correction of ZAP-70 immunodeficiency by intrathymic gene transfer. J Clin Invest 2005; 115: 2287-2295.

14 Roifman CM. Studies of patients' thymi aid in the discovery and characterization of immunodeficiency in humans. Immunol Rev 2005; 203: 143-155.

15 Stephan V, Wahn V, Le Deist F, Dirksen U, Broker B, Muller-Fleckenstein I et al. Atypical X-linked severe combined immunodeficiency due to possible spontaneous reversion of the genetic defect in T cells. $N$ Engl I Med 1996; 335: 1563-1567.

16 Nelson DM, Metzger ME, Donahue RE, Morgan RA. In vivo retrovirus-mediated gene transfer into multiple hematopoietic lineages in rabbits without preconditioning. Hum Gene Ther 1997; 8: 747-754.

17 Newbound GC, Cooper JR, O'Rourke JP, Baskin CR, Bunnell BA. Analysis of gene transfer efficiency of retrovirus producer cell transplantation for in situ gene transfer to hematopoietic cells. Exp Hematol 2001; 29: 163-173.

18 McCauslin CS, Wine J, Cheng L, Klarmann KD, Candotti F, Clausen PA et al. In vivo retroviral gene transfer by direct intrafemoral injection results in correction of the SCID phenotype in Jak3 knock-out animals. Blood 2003; 102: 843-848.

19 Ueda K, Hanazono Y, Shibata H, Ageyama N, Ueda Y, Ogata S et al. High-level in vivo gene marking after gene-modified autologous hematopoietic stem cell transplantation without marrow conditioning in nonhuman primates. Mol Ther 2004; 10: 469-477. 